\title{
Preputial circumcision performed with a new mechanical stapling tool. The "langhe disposable circumcision suture device". Preliminary experiences
}

\author{
Diego Pozza ${ }^{1}$, Carlotta Pozza $^{2}$, Augusto Mosca ${ }^{3}$, Mariangela Pozza ${ }^{1}$ \\ ${ }^{1}$ Studio di Andrologia e di Chirurgia Andrologica, Rome, Italy; \\ ${ }^{2}$ Department of FPM, Sapienza University, Rome, Italy; \\ ${ }^{3}$ U.O. Urologia ed Andrologia, Osp. S. Sebastiano, Frascati, Italy.
}

\begin{abstract}
Summary The Authors present their preliminary clinicumcision utilizing a new stapling tool.
\end{abstract}

KEY WORDS: Circumcision; Phimosis; Stapling surgical tool.

Submitted 17 July 2019; Accepted 29 July 2019

\section{INTRODUCTION}

Male circumcision was performed since 2300 BC in Egypt (1) and is one of the most common surgical procedures performed on males for religious, ethical, sexual or medical reasons (2). Circumcision is undertaken using a variety of surgical methods (3). Since the years '80, "Stapler" tools that allow to make sections and sutures of circular and longitudinal organs in very short time have become a "standard" for many surgical branches. Genital surgery, due to the narrowness of the operative field and the limited dimensions of the organs, did not admit the use of these mechanical staplers.

We want to present our preliminary experiences on the use of the "Langhe disposable circumcision suture device" (LDCSD), which is an innovative mechanical "Stapler" tool to carry out a circumcision (4).

\section{Case report}

We utilized the LDCSD in 20 patients (pts) aged 14 to 80 years with congenital phimosis, redundant prepuce or balanopostitic outcome (Figure 1). In the Operating Room local anesthesia or anesthesiological sedation is performed according to age and clinical data of the pts. After disinfection it is checked that the preputial frenulum is sufficiently extensible, otherwise it is engraved. The part of the instrument, conformed like a small cup with a stem, is introduced under the prepuce to completely cover the gland. The prepuce is fixed to the stem with a safety buckle, the stem of the instrument is introduced into the handpiece until it protrudes. The screw is turned until the hand-

Figure 1. piece is fixed to the Cup under the prepuce. The two handles of the handpiece are firmly tightened so that there is a further compression and section of the cutaneous and mucosal layers. The compression of the handles determines their circular section and suture with 12 staples with perfect mechanical and hydraulic seal. After 1 minute the screw is unscrewed to distance the two parts and free the perfectly circumcised and sutured penis (Figure 2). The prepuce is wrapped with sterile gauze and a strong circular pressure is maintained with the fingers for 4-5 minutes. The penis is tightly bendaged and the pt. is returned to bed with the bandage which is maintained for at least 2-3 hours for hemostatic purposes. If there are no signs of bleeding when the bandage is removed, the patient is sent home. If, on the other hand, a bleeding is observed, a local compression or an absorbable stitch should be applied. The first 3 cases required special prudence and attention; the 17 following pts were performed with simple local anesthesia and in 3 pts ( $<20$ years) with sedation. Operating times varied between 5 and 7 minutes.

A. The Box containing the LDCSD.

$B$. The Instrument ready for use.

C. The 12 staples assembled in the circular resection part.

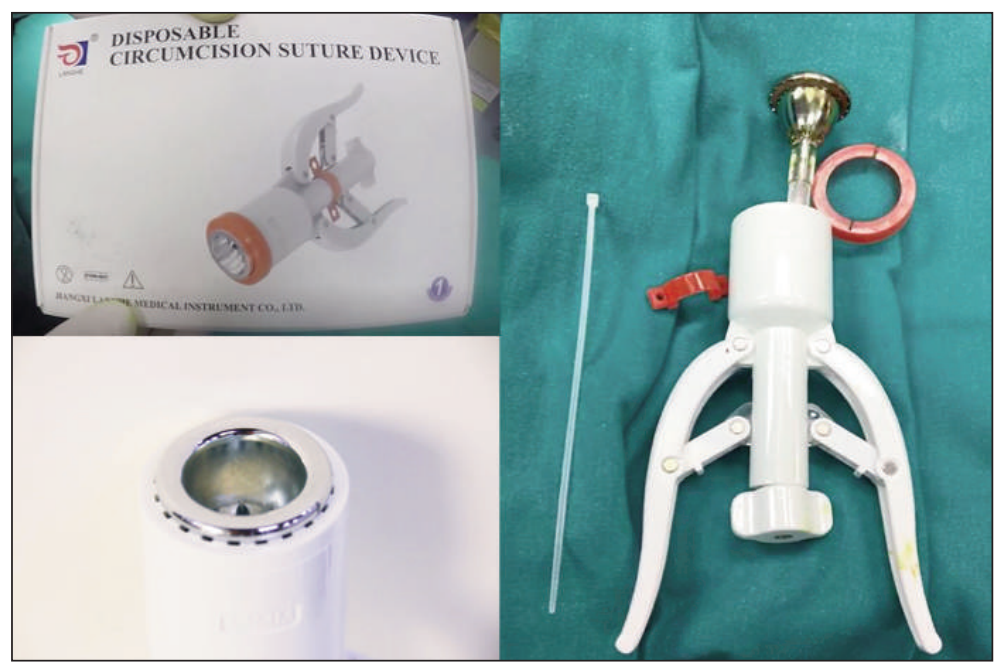

No conflict of interest declared. 


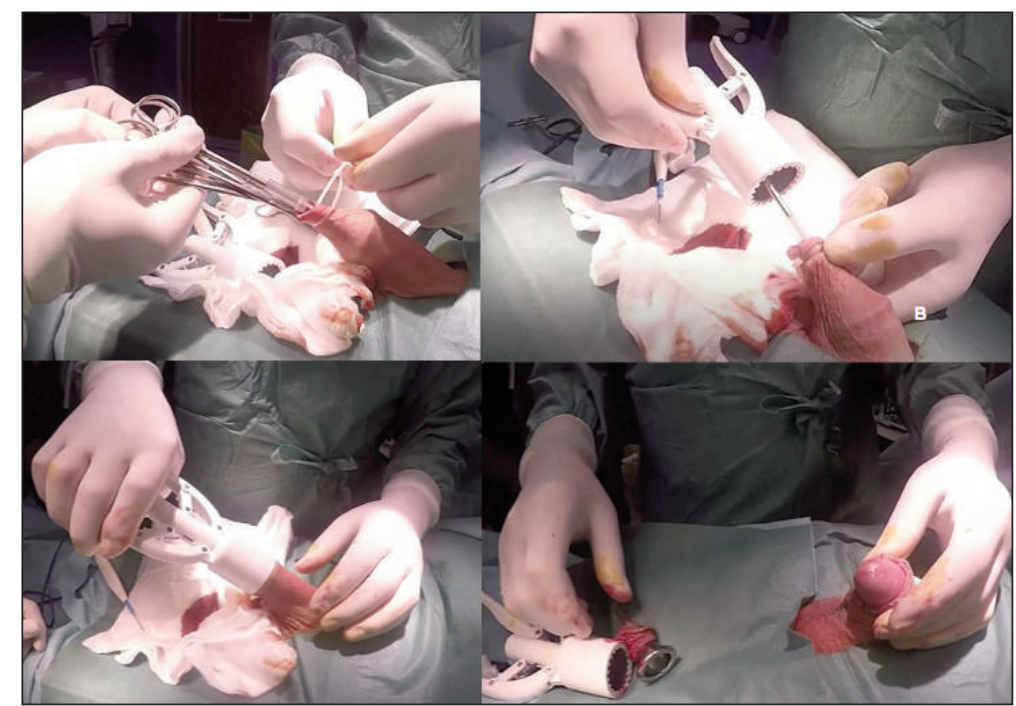

\section{Figure 2.}

A. The prepuce is fixed around the metallic stem.

$B$. The stem is introduced into the handpiece.

C. The handpieces are strictly tightened.

$D$. The system is disassembled; the prepuce has been cut.

We have never observed any major complications. No significant intraoperative blood loss. In 2 cases we have prudentially applied few absorbable suture stitches. Metallic staples fell spontaneously after 15-25 days. In 2 cases after 30 days we removed some staples still present with a simple and painless ambulatory maneuver. All pts reported full satisfaction concerning operative, postoperative, aesthetic and functional results (Figure 3).
Figure 3.

A. Result after 1 week in young patient with phimosis.

$B$. Result in a 80 years old patient after balanoposthitis.

C. The metallic staples.

D. Result in a young patient after one month.

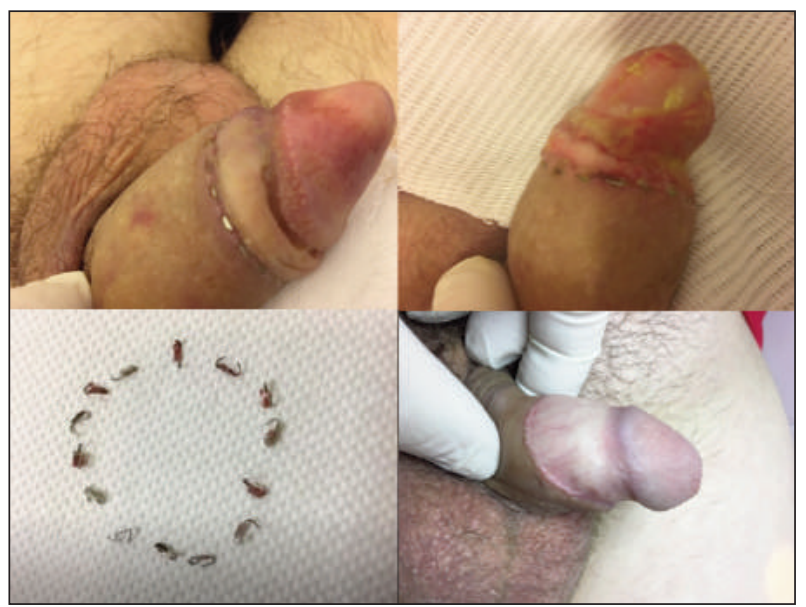

\section{Conclusions}

The LDCSD with his advantages of simple and easier manipulation, shorter operation time, fewer complications, better cosmetic results, could be considered a useful tool to carry out a rapid, aesthetic, effective and safe circumcision.

\section{REFERENCES}

1. Meijer B, Butzelaar RM. Circumcision from a historical perspective. Ned Tijdchr Geneeskd. 2000; 144:2504.

2. Bronselaer GA, Schober JM, Meyer-Bahlburg HF, et al. Male circumcision decreases penile sensitivity as measured in a large cohort. BJU. 2013; 111:820.

3. Featherstone NC, Murphy FL. Paediatric suturless circumcision and modified circumcision: video demostration. J Pediatr Urol. 2012; 8:240.

4. Lv BD, Zhang SG, Zhu XW, et al. Disposable circumcision suture device: clinical effect and patient satisfaction. Asian J Androl. 2014; 16:453.

\section{Correspondence}

Diego Pozza, MD (Corresponding Author)

diegpo@tin.it

Mariangela Pozza, MD

Studio di Andrologia e di Chirurgia Andrologica

Via B. Gozzoli, 62H - 00142 Roma (Italy)

Carlotta Pozza, MD

Department of FPM, Sapienza University, Roma (Italy)

Augusto Mosca, MD

U.O. Urologia ed Andrologia, Osp. S. Sebastiano, Frascati (Italy) 